\title{
Experimental Evaluation of Flank Wear in Dry Turning from Accelerometer Data
}

\author{
R. Serra \\ INSA Centre Val de Loire, Laboratoire de Mécanique et Rhéologie / CEROC, Blois, France \\ W. Rmili \\ Université François Rabelais, Laboratoire de Mécanique et Rhéologie / CEROC, Tours, France
}

\begin{abstract}
(Received 18 December 2013; accepted 14 November 2014)
This paper presents an experimental evaluation of cutting tool wear based on vibration signals to study the wear development of the cutting tool insert in order to increase machining performance. To achieve this purpose, tool life tests according to ISO standard 3685 have been performed in turning operation under dry cutting conditions. The wear development was studied for thirty cutting tool inserts selected from the same production batch, and used in strictly identical experimental conditions for a statistical study. The vibration signatures acquired during cutting processes have been analysed and contrasted using three signal processing techniques: statistical, temporal and spectral analysis. Results have shown that the dynamic characteristics of tool vibration changed with cutting tool wear development. Furthermore, this vibration analysis exhibited a strong correlation, during machining, between the evolution of flank wear land and vibration responses.
\end{abstract}

\section{INTRODUCTION}

In the machining process, the quality of the workpiece, like dimensional accuracy and surface roughness, depends mainly on the state of the cutting tool. Monitoring of the cutting tool condition therefore plays a significant role in achieving consistent quality and controlling the overall cost of manufacturing. High performance machining consequently requires a good evaluation of the cutting tool wear. ${ }^{1}$ A wide variety of sensors, modelling, and data analysis techniques have been developed for this purpose. ${ }^{2-4}$ In general, the cutting tool wears on the two contact zones, and the wear phenomenon appears in several forms, such as flank wear, crater wear, chipping, etc. ${ }^{5}$ These forms depend essentially on cutting tool characteristics, workpiece material, cutting conditions, and types of machining. ${ }^{6}$ Crater wear occurs on the rake face of the tool (see Fig. 1) where the chip moves with a frictional force under heavy loads and high temperatures, leading to wear. Crater wear is usually avoided or minimized by selecting cutting conditions and a cutting tool that does not have an affinity for diffusion with the workpiece material. Flank wear is caused by friction between the flank face of the cutting tool (see Fig. 1) and the machined workpiece surface. At the tools flank-workpiece interface, tool particles adhere to the workpiece surface and are periodically sheared off. This leads to the loss of cutting edge and affects the dimensional accuracy and surface finish quality. An established industrial standard on tool wear is ISO 3685 (1993). ${ }^{7}$ Figure 1 shows the typical tool wear profile according to this standard. In this figure, the wear of the major cutting edges of the tool can be divided into four regions:

- Region $\mathrm{C}$ is the curved part of the cutting edge at the tool corner, which marks the outer end of the wear land;

- Region $\mathrm{B}$ is the remaining straight part of the cutting edge between Region C (consisting of uniform wear land);
- Region $\mathrm{A}$ is the quarter of the worn cutting edge length farthest away from tool corner;

- Region $\mathrm{N}$ extends beyond the area of mutual contact between the tool workpiece for approximately 1 to $2 \mathrm{~mm}$ along the major cutting edge. The wear in this region is of the notch type and contributes significantly to surface roughness.

Under normal machining conditions, flank wear is regarded as the most preponderant. According to ISO 3685 (1993), measurement of the width of flank wear land (VB) is the most commonly used parameter to evaluate cutting tool lifespan. ${ }^{5,6}$ If the profile is uniform, the tool can be used unless the average value of VB is greater than $0.3 \mathrm{~mm}$. For uneven wear, the maximum wear land width (VBmax) should be less than $0.6 \mathrm{~mm}$.

The development of this wear form on the cutting tool is not a random phenomenon. A typical evolution of flank wear land (VB) with cutting time for different cutting velocities is shown in Fig. 2. ${ }^{5}$ The curve can be divided into three zones during its lifetime:

- Initial wear zone, where the initial flank wear land is established (primary wear zone);

- Steady wear zone, where wear progresses at a uniform rate (secondary wear zone);

- Accelerated wear zone, where wear occurs at a gradually increasing rate (tertiary wear zone).

Generally, the evaluation of cutting tool wear can be made in two ways: direct and indirect methods. The direct methods involve measuring the state of tool wear by the classical vision or optical systems such as CCD-based cameras, equipped optical microscopes, and/or white light interferometers. ${ }^{8,9}$ These methods have an advantage of measuring exact 


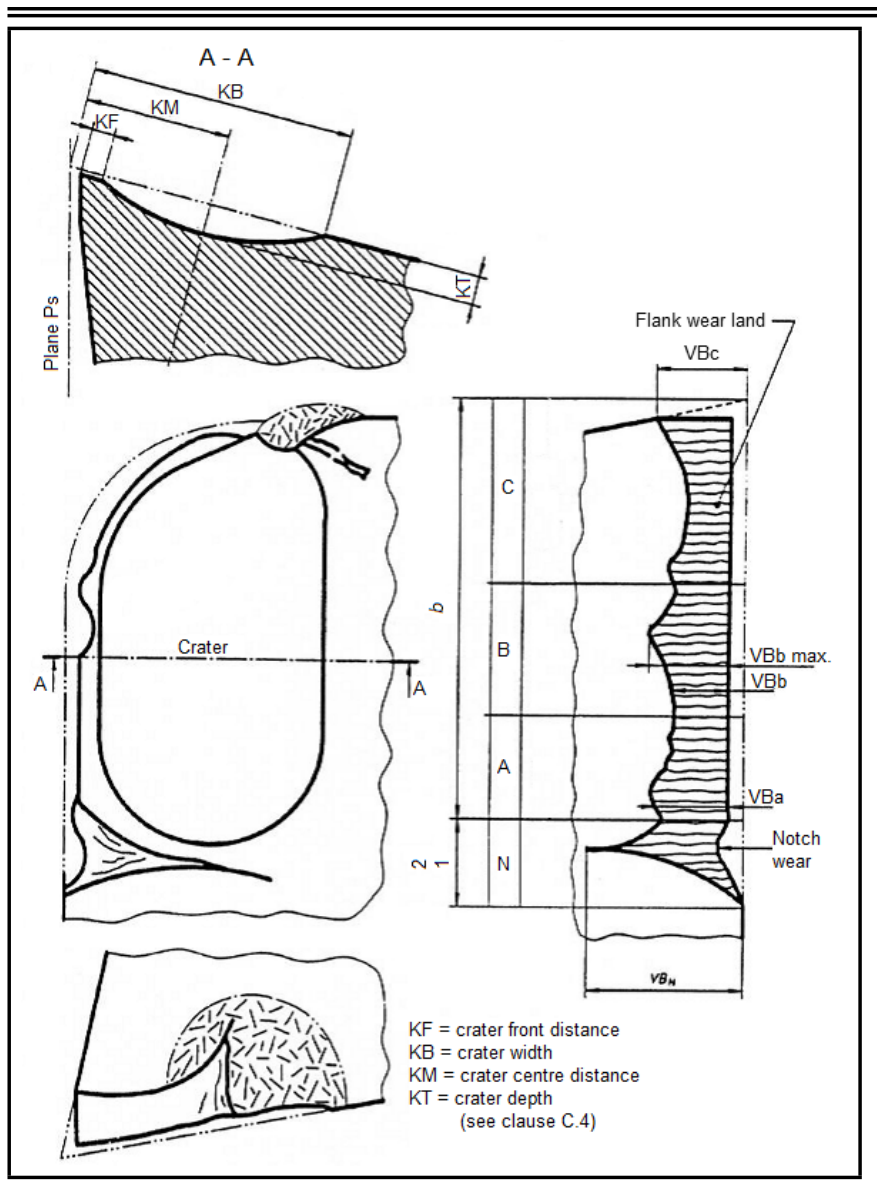

Figure 1. Progressive tool wear geometry according to ISO standard 3685 (1993).

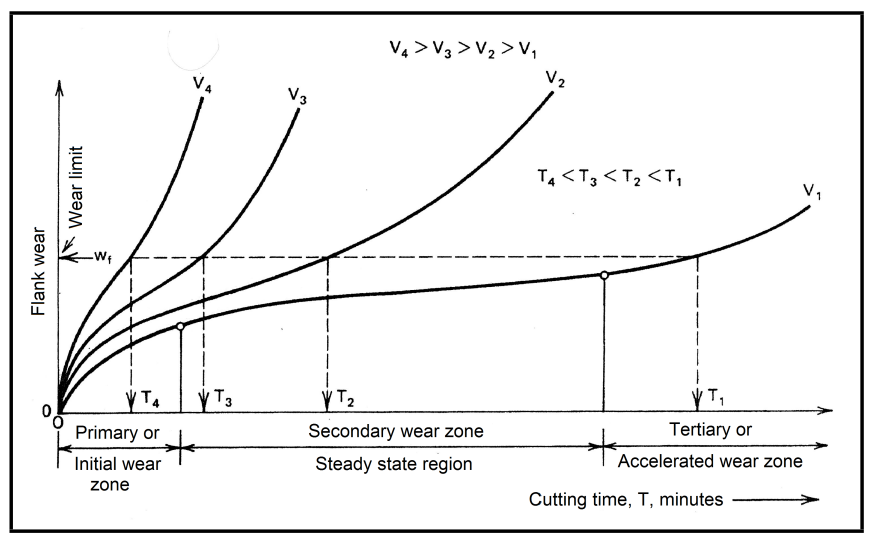

Figure 2. Evolution of flank wear related to cutting time (Altintas, 2000).

geometric changes due to wearing of the cutting tool. However, these methods require production to stop for the evaluation of the cutting tool wear, and in most cases it is too late to limit its effects. The indirect methods are achieved by the correlation of suitable sensors to cutting tool wear. ${ }^{10}$ In this case, the cutting tool wear is not obtained directly, but estimated from the signal of the measurement feature. The features are extracted through signal processing techniques for evaluating its corresponding wear state. Direct and indirect methods, discussed in the work by Byrne, et al., ${ }^{11}$ are based on tool wear measurement using various tool wear sensors, radio isotopes as tracers, chemical analysis of tool particles carried by chips, detection probe microscopes, and weighing of the tool before and after machining, ${ }^{12}$ acoustic emissions, ${ }^{13}$ cut-

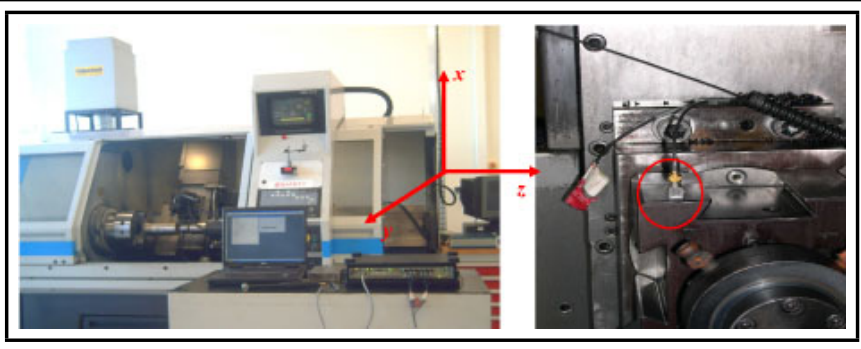

Figure 3. Machine tool used, data acquisition system, directions and localization of a tri-axial accelerometer mounted on tool holder.

ting forces, ${ }^{14,15}$ optical displacement sensors, ${ }^{16}$ spindle current, ${ }^{17}$ strain measurements, ${ }^{18}$ tool vibrations, ${ }^{2,18,19}$ etc. But many of them are difficult to implement in the real-time monitoring of a production system. However, sensing accelerometer signals from the cutting process is one of the most promising methods. The wide range of techniques available for characterizing the tool wear, either during the machining process or after, indicates that no technique has gained widespread acceptance, either in research or in industrial practice. This is not surprising, since it is clear that each method suffers from numerous disadvantages. The final decision on what method is appropriate for a particular application rests with the user.

In this context, a collaboration project between a world leader in cutting tool insert manufacturing and our laboratory was carried to develop a reliable and applicable evaluation based on vibratory analysis to characterize in terms of wear a new cutting tool insert. In this study, the vibratory signatures produced during the turning process and acquired by a tri-axial accelerometer, mounted on the tool holder, were analysed using three signal processing methods: statistical analysis, time domain analysis, and spectral analysis. The selected processing methods are simple to operate in an industrial environment, and do not require protracted computing time. The results issued from vibratory analysis were compared with the off-line direct control of cutting tool wear and contrasted in a sensitivity matrix.

\section{METHODOLOGY}

\subsection{Experimental Set-up and Data Acquisition}

\subsubsection{Machining Details}

In this study, experiments were conducted for the turning process, and the machining operations have been achieved on a $2.4 \mathrm{~kW}$ power SOMAB model 500 lathe (CNC), as shown in Fig. 3. The cast iron workpiece material chosen was an AISI CL 40 gray iron for its good machinability, wear resistance, and vibration damping capacity. The cutting tool insert was made by Safety Company of the ISO CNMG 120408 with a MT-CVD inner coating (TiCN/Al2O3/TiN multilayer structure) and mounted on ISO DCLNL 2525M12 tool holder.

Cutting operations were performed in dry conditions (without applying coolant). All cutting experiments were performed under the following cutting conditions according to manufacturer recommendations and held under the same cutting conditions in order to examine the experimental repeatability: cutting speed $V_{c}=340 \mathrm{~m} / \mathrm{min}$, feed rate $f=0.18 \mathrm{~mm} / \mathrm{rev}$, and depth of cut $a_{p}=1.5 \mathrm{~mm}^{6,20}$ 


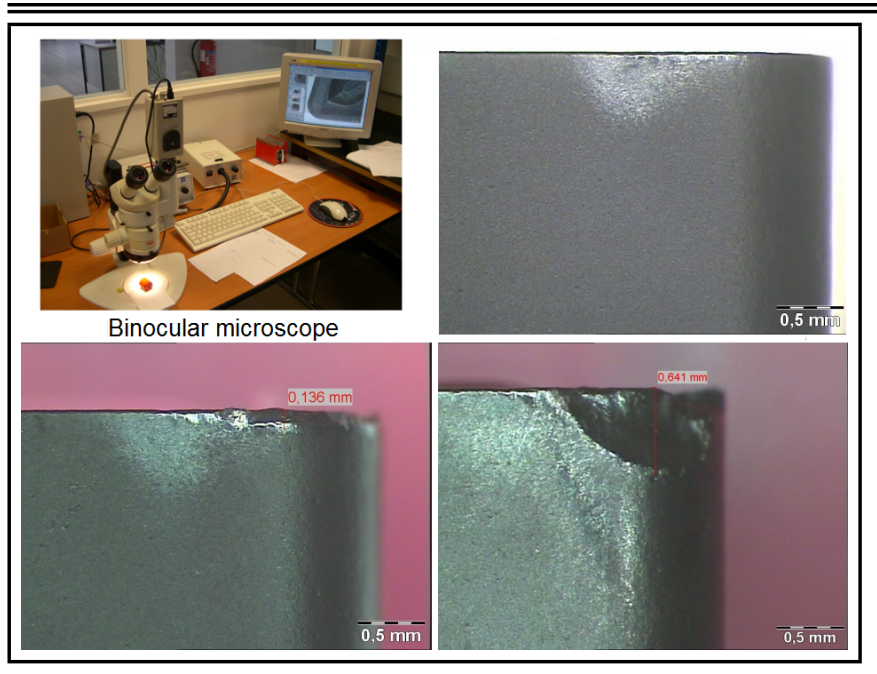

Figure 4. Binocular optical microscope of flank wear insert after machining 1 minutes: (a) 8 minutes (b) and 11 minutes (c) of tool life $(4 \times$ magnification).

\subsubsection{Flank Wear Measurement}

Tool life tests according to ISO 3685 (1993) were performed. ${ }^{7}$ The assessment of flank wear is accomplished by its direct measurement. From the first use up to the end of its lifespan, the cutting tool state was controlled over regular intervals (after each cutting test). Tool wear was measured carefully using a modern CCD Camera linked to a binocular optical microscope for the picture acquisition in an integrated desktop PC with a commercial digital image processing software installed (AnalySIS). A high resolution picture (768 pixels $\times 576$ pixels) of the flank face at $4 \times$ zoom was taken and imported into AnalySIS software, in order to further measure VB. Wear measurements were made along the length of the active cutting edge. Each test was repeated three times, and an average was calculated to ensure precision and repeatability, as shown in Fig. 4.

A specific optical technique based on white light interferometry is a modern technique for accurately and precisely measuring the 3D surface of the cutting tools. This technique uses the vertical scanning interferometer (VSI) performed on a Wyko NT-2000 optical profiler. To evaluate the degree of tool wear, the mean of the flank wear width (VB) was measured by scanning the major flank (scanning size is $0.60 \times 0.46 \mathrm{~mm}^{2}$ ), as illustrated in Fig. 5 below.

\subsubsection{Accelerometer Data Acquisition}

In order to study the correlation between tool vibration and tool wear, it is necessary to first analyse how tool vibration acts on a machined workpiece. As mentioned by Tobias ${ }^{21}$ and after by Thomas, et al., ${ }^{22}$ the variation of cutting forces generated when the tool and workpiece come into contact produce significant structural deflections. Consequently, the chip thickness varies in proportion to the tool deflection $x(t)$. Assuming a simple model, the vibration of the tool structure may be described by the following dynamic equation:

$$
m \ddot{x}(t)+c \dot{x}(t)+k x(t)=f(t) ;
$$

where $m, c$, and $k$ are the effective mass, damping, and stiffness, respectively, of the tool structure. The tool deflections $x(t)$ are obtained by measuring the acceleration amplitudes on the tool during the machining process, using a $B \& K$ tri-axial

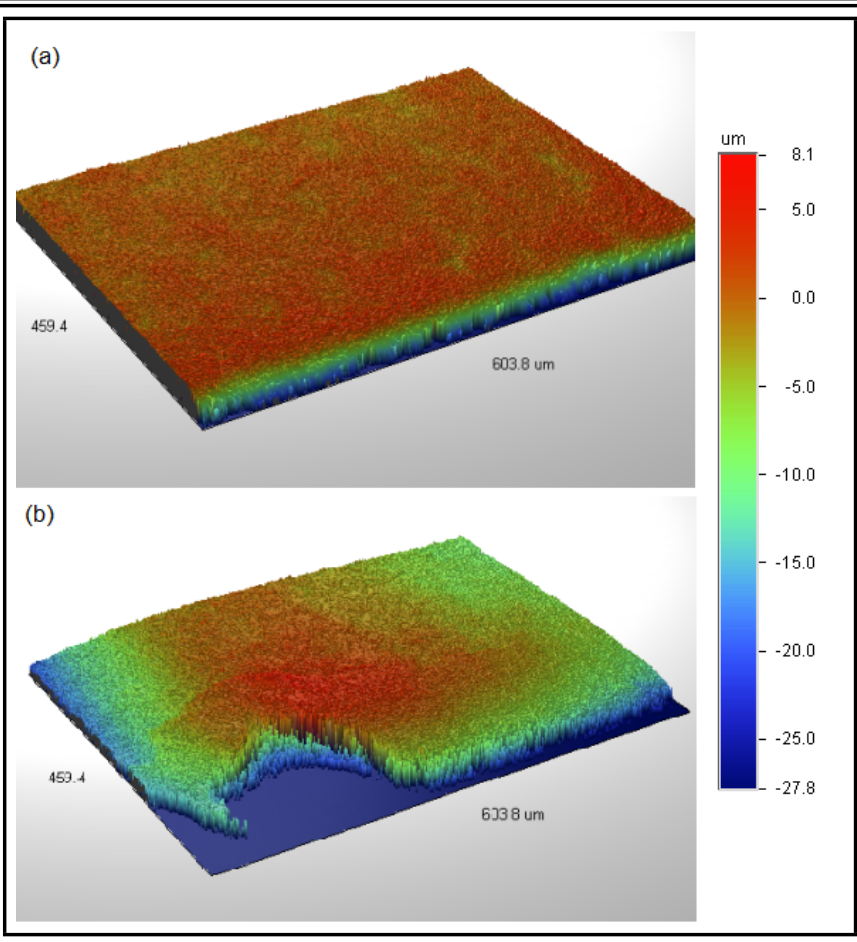

Figure 5. 3D interferometer scanning of new insert (a) and worn insert (b).

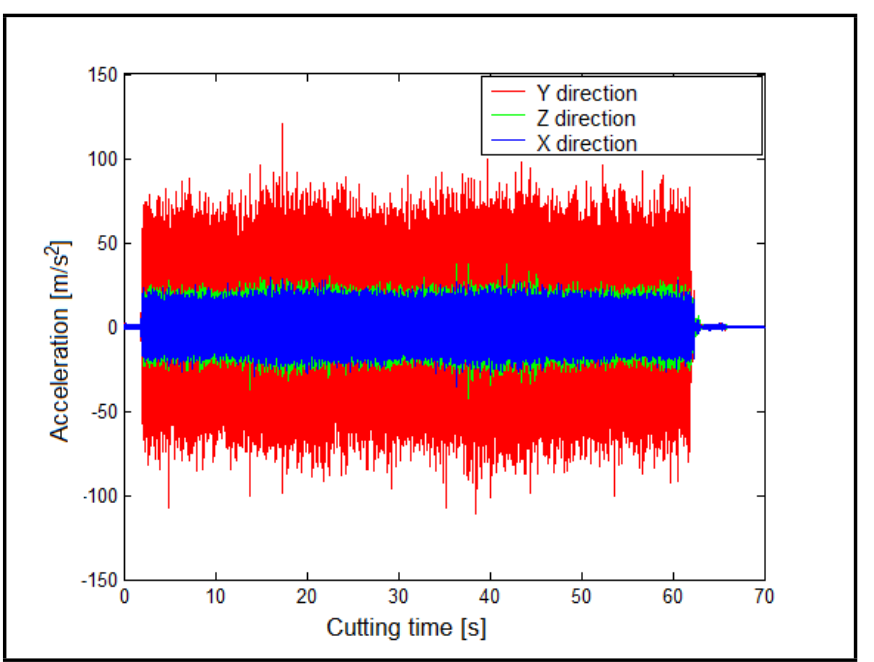

Figure 6. 3D interferometer scanning of new insert (a) and worn insert (b).

piezoelectric accelerometer (type 4520) with a sensitivity of $1.032 \mathrm{mV} / \mathrm{ms}^{-2}$ according $X$ direction, $1.067 \mathrm{mV} / \mathrm{ms}^{-2}$ according $\mathrm{Y}$ direction, and $1.045 \mathrm{mV} / \mathrm{ms}^{-2}$ according $\mathrm{Z}$ direction. This accelerometer was fixed on the tool holder, to be in the fixed part of the machine and near of the cutting area, as shown in Fig. 3.

All vibratory signatures produced during the dry turning process were measured in real time, recorded, and analysed with a B\&K Pulse Multi-channel analyser connected directly to the desktop PC in the three directions: the axial or feeding direction (Z), the tangential (to the rotating workpiece) or cutting direction $(\mathrm{Y})$, and the radial direction $(\mathrm{X})$, as shown in Fig. 6. This generates a large number of features, which was helpful to acquire maximum information about the cutting tool wear.

Signals issued from the accelerometer were acquired for a 70 seconds (including 60 seconds of cutting time) and sampled at 16,384 Hz. Each signal contained 1,146,600 samples. 
Collected data were stored directly on the PC hard drive. Signal processing methods were performed from raw data using our interactive MATLAB interface.

\subsection{Signal Processing Analysis}

Exploiting vibratory signals acquired during machining allows the estimation of the cutting tool wear and the follow-up of its evolution by calculating several parameters. Three signal processing techniques based on statistical analysis (variance), time domain analysis (envelope), and spectral analysis (smoothed mean periodogram) are chosen to evaluate a flank wear from accelerometer data. These techniques are very common and do not require qualified personnel or investment in expensive equipment. The sensitivity matrix will compare these methods.

\subsubsection{Statistical Analysis}

The variance $\sigma^{2}$ of the accelerometer signal recorded $x_{q}$ such as $x_{q}[n]=\left(x_{q}(1), x_{q}(2), x_{q}(3), x_{q}(N)\right)$, where $n$ is a sample and $N$ is the number of samples obtained at periodic time intervals of $T$ seconds, maintains the relevant information about the process and tool conditions. It is defined by:

$$
\sigma^{2}=E\left[x_{q}^{2}\right]-\left(E\left[x_{q}\right]\right)^{2} .
$$

\subsubsection{Time Domain Analysis}

The time domain method described below provides a rapid quantification of the tool wear during the turning process. The envelope represents the slowly varying features of the signal and is calculated from the magnitude discrete-time analytic signal modulus $\left|Z_{q}\right|$, defined by:

$$
Z_{q}=x_{q}+j \tilde{x}_{q}
$$

where a real part $x_{q}$ is the original data, and the imaginary part $\tilde{x}_{q}$ contains the Hilbert transform of the signal implemented in a MATLAB as function "hilbert()".

In fact, the analytic signal $Z_{q}$ for a sequence $x_{q}$ has a onesided discrete Fourier transform - that is, negative frequencies are zeros. To approximate the analytic signal, Hilbert calculates the Fast Fourier transform (FFT) of the input sequence, replaces those FFT coefficients that correspond to negative frequencies with zeros, and calculates the inverse FFT of the result. Recall that the convolution kernel $h[n]$ for the transfer function of the Hilbert transform can be calculated through the inverse Fourier transform: ${ }^{23}$

$$
h=\left\{\begin{array}{l}
\frac{2}{\pi} \frac{\sin ^{2}(\pi n)}{n}, \quad n \neq 0 \\
0, \quad n=0
\end{array} .\right.
$$

The analytic signal is useful as an estimates for the amplitude envelope $\mathbf{A}$ of the signal $x_{q}$ in discrete-time domain. Notably, it was used to evaluate the tool wear from onset to the ending of tool life.

\subsubsection{Spectral Analysis}

The simplest way to determine the frequency domain information is by using the Fast Fourier Transform (FFT) of the

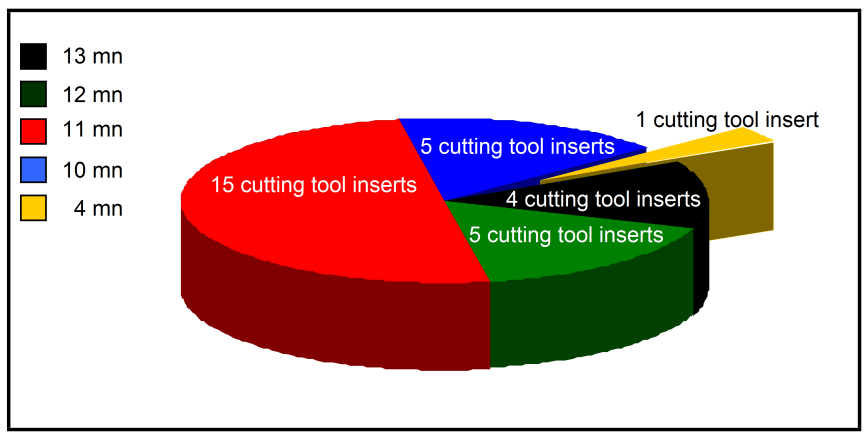

Figure 7. Lifespan of thirty cutting tool inserts used in experiments.

measured signal. But more advanced statistical signal processing techniques, such as computing the smoothed mean periodogram so-called power spectral density (PSD) with Welchs method, ${ }^{23}$ can yield better results. In spectral domain, the PSD $S_{X}(f)$ of the signal $X(t)$ is determined by the relation:

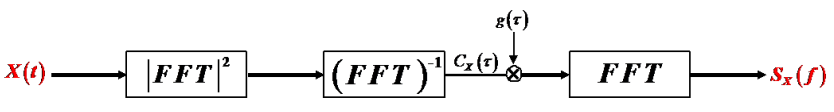

where $C_{X}(\tau)$ is the correlation function of $X(t)$, and $g(\tau)$ is a Hanning window.

\section{RESULTS AND DISCUSSION}

\subsection{Tool Wear Control}

As expected, the experimental results showed that the dominant tool wear was the flank wear (VB). Damage observed on the rake face, such as width and depth of crater wear, indicates that the crater wear was not affected by wear mechanisms except some frictions due to chip contact during cutting process. It is relatively weak comparing to flank wear (VB) in accordance with the other studies used in this paper, and therefore the chosen criterion of tool life is the flank wear.

In accordance with the ISO Standard 3685, an average width of flank wear land (VB) of $0.3 \mathrm{~mm}$ (considered to be regularly worn) is adopted for the tool life criterion, as shown in Fig. 5(b). For the same insert, if the criterion is not achieved, the tests continue in order to provide wear data for use in the wheel wear evaluation procedure, as shown Figs. 4(a) and (c). Then, experiments were stopped when flank wear (VB) reached or exceeded the value of flank wear limit. Figure 4(c) shows the flank wear after the eleventh cutting passes. It can be seen that the flank wear was quite severe. The list of all experiments in which the flank wear limit is measured is shown in Table 1.

\subsection{Dispersion Analysis}

The result obtained shows that although the cutting tool inserts belong to the same production batch and are used under the same experimental conditions, their end of lifetime varies from 4 to 13 minutes, which shows the complexity of the phenomenon of wear in an industrial context and the manufacturing process dispersion.

In accordance with the results given in Table 1, the lifespan dispersion of the same thirty cutting tool inserts studied in the same conditions is shown in Fig. 7.

From the representation shown in Fig. 7, the thirty cutting tool insert lifespan dispersion could be divided into four prin- 


\begin{tabular}{|c|c|c|c|c|}
\hline $\begin{array}{c}\text { Insert } \\
N^{o}\end{array}$ & $\begin{array}{c}\text { Machined work- } \\
\text { piece diameter } \\
{[\mathrm{mm}]}\end{array}$ & $\begin{array}{l}\text { Machined } \\
\text { length } \\
{[\mathrm{mm}]}\end{array}$ & $\begin{array}{l}\text { Time } \\
\text { limit } \\
{[\mathrm{min}]}\end{array}$ & $\begin{array}{c}\text { Flank wear } \\
\text { limit } \\
{[\mathrm{mm}]}\end{array}$ \\
\hline 1 & 185 & 105.30 & 13 & 0.31 \\
\hline 2 & 182 & 107.04 & 13 & 0.30 \\
\hline 3 & 179 & 108.83 & 12 & 0.32 \\
\hline 4 & 176 & 110.69 & 13 & 0.40 \\
\hline 5 & 173 & 112.60 & 13 & 0.40 \\
\hline 6 & 170 & 114.59 & 11 & 0.40 \\
\hline 7 & 167 & 116.65 & 11 & 0.32 \\
\hline 8 & 164 & 118.78 & 11 & 0.60 \\
\hline 9 & 161 & 121.00 & 11 & 0.30 \\
\hline 10 & 158 & 123.29 & 11 & 0.37 \\
\hline 11 & 155 & 125.68 & 12 & 0.40 \\
\hline 12 & 152 & 128.16 & 11 & 0.41 \\
\hline 13 & 149 & 130.74 & 12 & 0.74 \\
\hline 14 & 146 & 133.43 & 11 & 0.71 \\
\hline 15 & 143 & 136.23 & 10 & 0.57 \\
\hline 16 & 140 & 139.15 & 11 & 0.62 \\
\hline 17 & 137 & 142.19 & 11 & 0.64 \\
\hline 18 & 134 & 145.38 & 4 & 0.40 \\
\hline 19 & 131 & 148.71 & 11 & 0.60 \\
\hline 20 & 128 & 152.19 & 11 & 0.40 \\
\hline 21 & 125 & 155.84 & 10 & 0.40 \\
\hline 22 & 122 & 159.68 & 11 & 0.42 \\
\hline 23 & 119 & 163.70 & 10 & 0.34 \\
\hline 24 & 116 & 167.94 & 12 & 0.52 \\
\hline 25 & 113 & 172.39 & 10 & 0.32 \\
\hline 26 & 110 & 177.10 & 11 & 0.55 \\
\hline 27 & 107 & 182.06 & 12 & 0.41 \\
\hline 28 & 104 & 187.31 & 11 & 0.60 \\
\hline 29 & 101 & 192.88 & 11 & 0.53 \\
\hline 30 & 98 & 198.78 & 10 & 0.40 \\
\hline
\end{tabular}

cipal duration groups: 10, 11, 12 and 13 minutes (an insert which lasted 4 minutes was considered an anomaly and was not taken into account in this study).

\subsection{Flank Wear Analysis}

Flank wear evolution was tracked by plotting a mean of flank wear width (VB) versus cutting time, as illustrated in Fig. 8, for each group. It was observed that the flank wear propagation was almost linearly related to the cutting time and then increased again quite rapidly, indicating that the severity of degradation was increased until tool collapse.

In order to provide wear data for use in the wheel wear evaluation procedure, the tool life was split into three regions (see Fig. 8). It can be clearly seen that the wear trend obeys the universal wear law of any mechanical workpiece (initial wear zone, steady state wear zone, and accelerated wear zone), according to the research referenced in this study (see Fig. 2).

Indeed, the wear-time diagram shows that it is possible to distinguish the three domains for all groups: initial wear phase of the insert, from the first experiment up to the $3^{\text {rd }}$ experiment; a wear stabilization zone where the flank wear increase uniformly, from the $3^{\text {rd }}$ experiment up to the cutting time between $8^{\text {th }}$ and $10^{\text {th }}$ experiment; and finally a tool wear acceleration phase where the wear rate increases rapidly, crossing the exceeded value of flank wear. Furthermore, all cutting tool inserts had the same behaviour before reaching the wear acceleration. Each group was characterized by its own local and specific stabilization/acceleration transition. However, using the direct control, all these transitions could be localized between 9 and 10 minutes of cutting time. In the following section, the application of signal processing methods is shown,

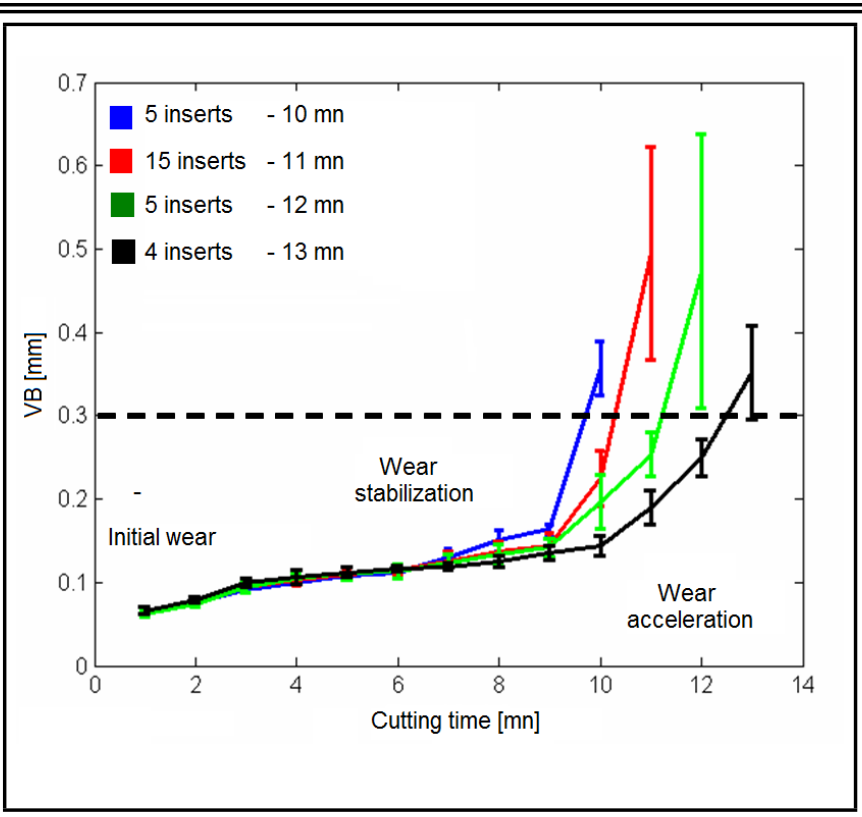

Figure 8. Flank wear (VB) according to the cutting experiment for each insert group.

which can be used to precisely determine the flank wear. This is helpful in industrial applications to predict the end of tool life and preserve a good quality of the product.

\subsection{Signal Analysis}

The evaluation of the cutting tool wear development was conducted by analysing the vibratory signature generated during the dry turning process. The estimation of the cutting tool wear was obtained by calculating three signal processing analyses: variance (Fig. 9), envelope (Fig. 10), and PSD (Fig. 11), in order to be considered as tool wear indicators in real time monitoring strategies.

\subsubsection{Variance and Tool Wear}

In Fig. 9, the Y-direction is difficult to exploit because of high levels of the recorded signal. In the $\mathrm{X}$ - and Z-directions, the evolution of the variance from the beginning to the end of machining is very close; all the groups have the same behaviour. The transition, or collapse, can be estimated at the $10^{\text {th }}$ minute. From this state, each group has its own evolution up to the end of the tool life. In fact, as the flank wear increased, the variance increased gradually. Hence, the variance can be used as a significant parameter for the evaluation of the cutting tool wear.

\subsubsection{Envelope and Tool Wear}

As for the variance, the levels recorded in the Y-direction for the envelope parameter were raised and did not allow us to establish a correlation with the cutting tool wear. The evolution of the envelope according to the X-direction was most sensitive to the deterioration of the tool state. The three conventional phases of tool wear (initial wear zone, stabilization wear zone, and acceleration wear zone) could be distinguished. It can be seen that the envelope increased gradually as the flank wear. Consequently, the envelope can be used as a significant parameter for the evaluation of the cutting tool wear. Finally for this method, of the three directions, X-direction seems to 


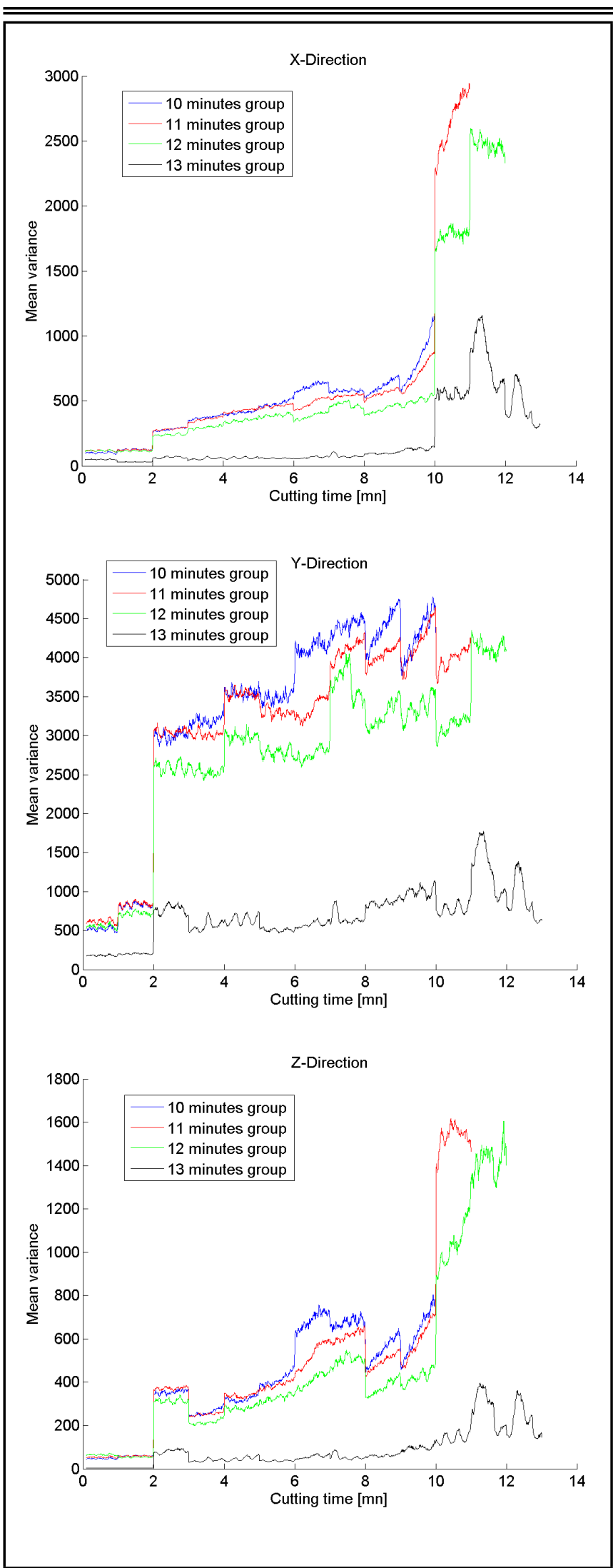

Figure 9. Variance versus experiments for each insert group.

be the most adapted direction to the evaluation of the wear of the cutting tool.

In addition, for both statistical and temporal analysis, the level of the group of 13 minutes is definitely different from the other groups, whereas the tests were strictly identical, and the measuring chain has been the same during all the tests (same
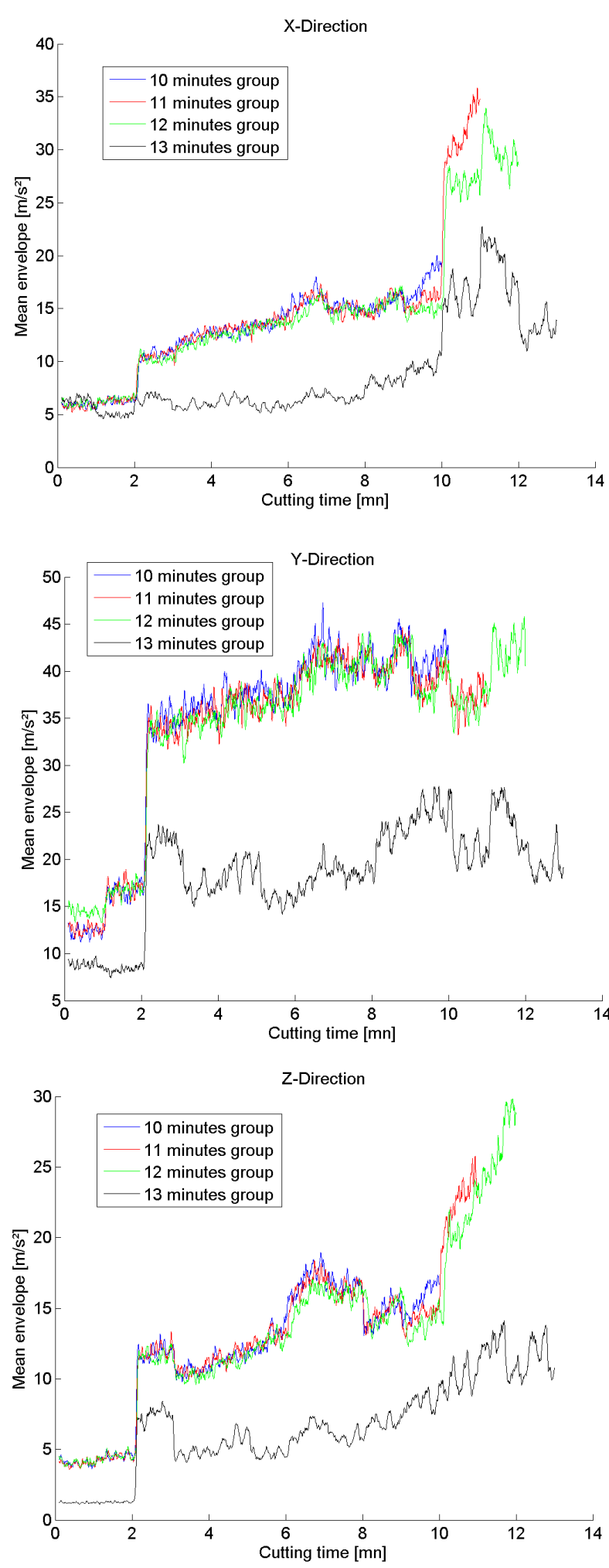

Figure 10. Envelope versus experiments for each insert group.

sensor, same cable, same analyser, same process, and same configuration). This shows the complexity of the manufacturing process phenomenon. It can be noted that the groups having longest tool life were also those having the lowest acceleration level. 


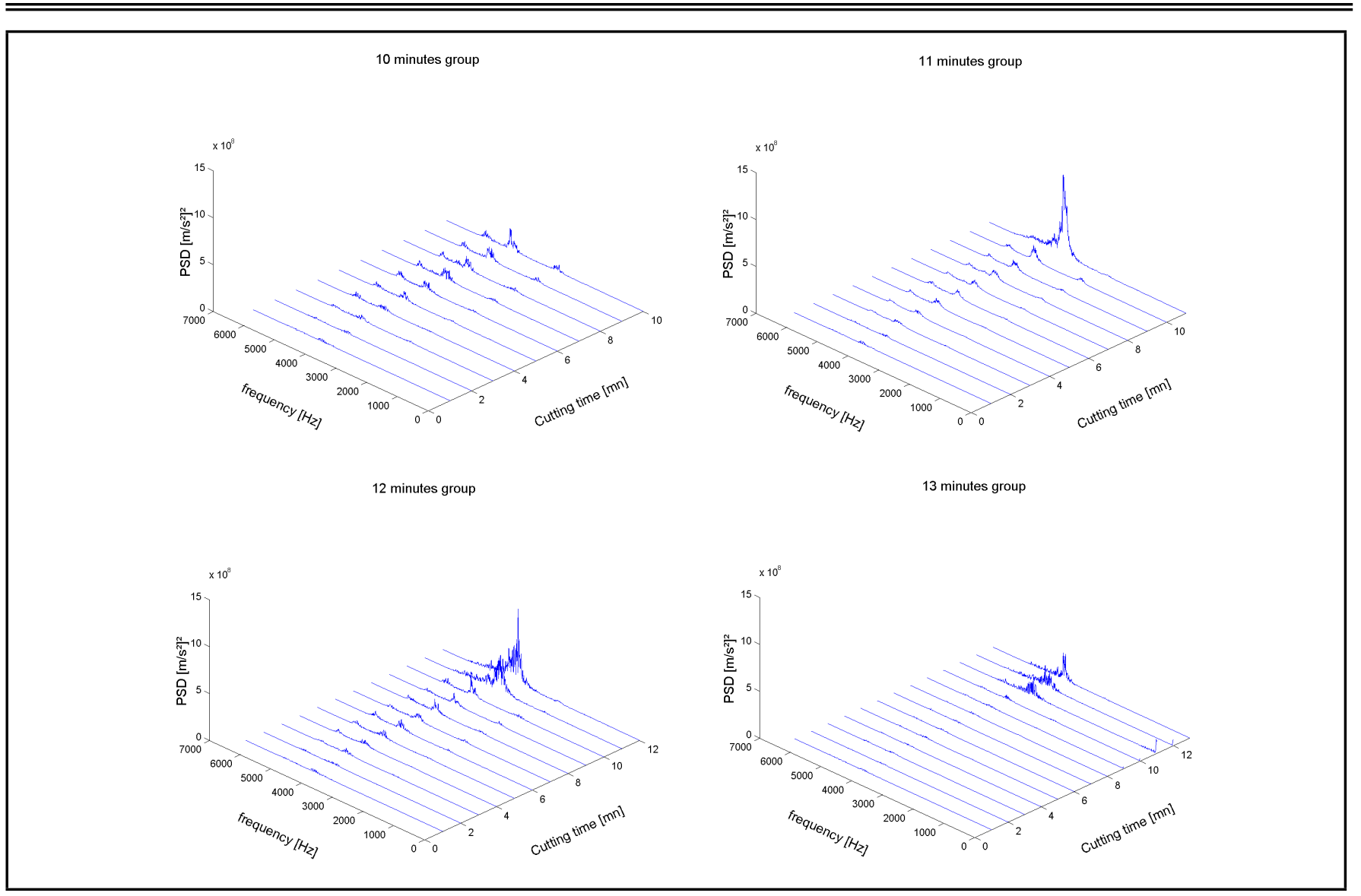

Figure 11. PSD vibration spectra vs experiments for each insert group, respectively, according to X-direction.

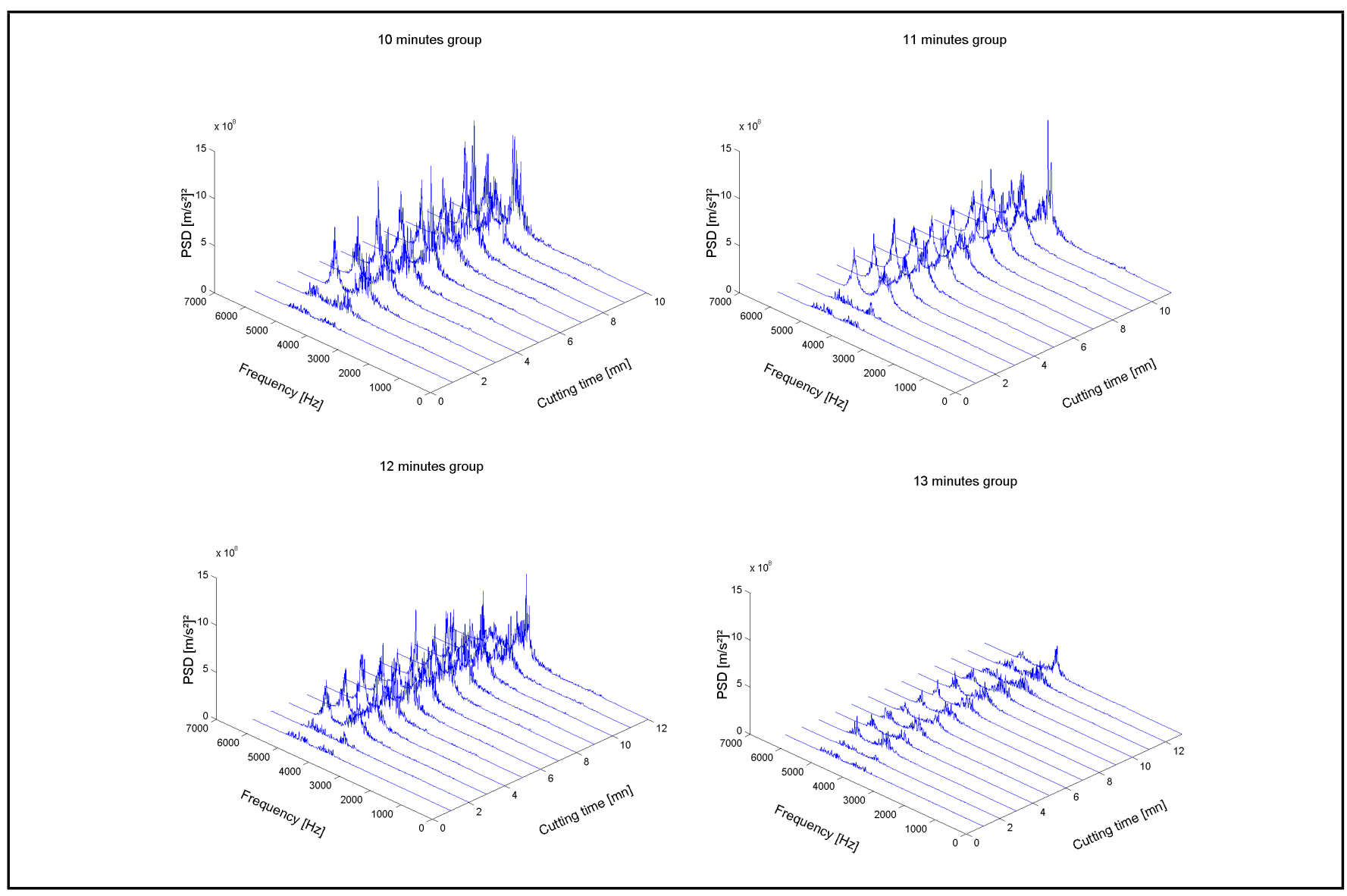

Figure 12. PSD vibration spectra vs experiments for each insert group, respectively, according to Y-direction. 


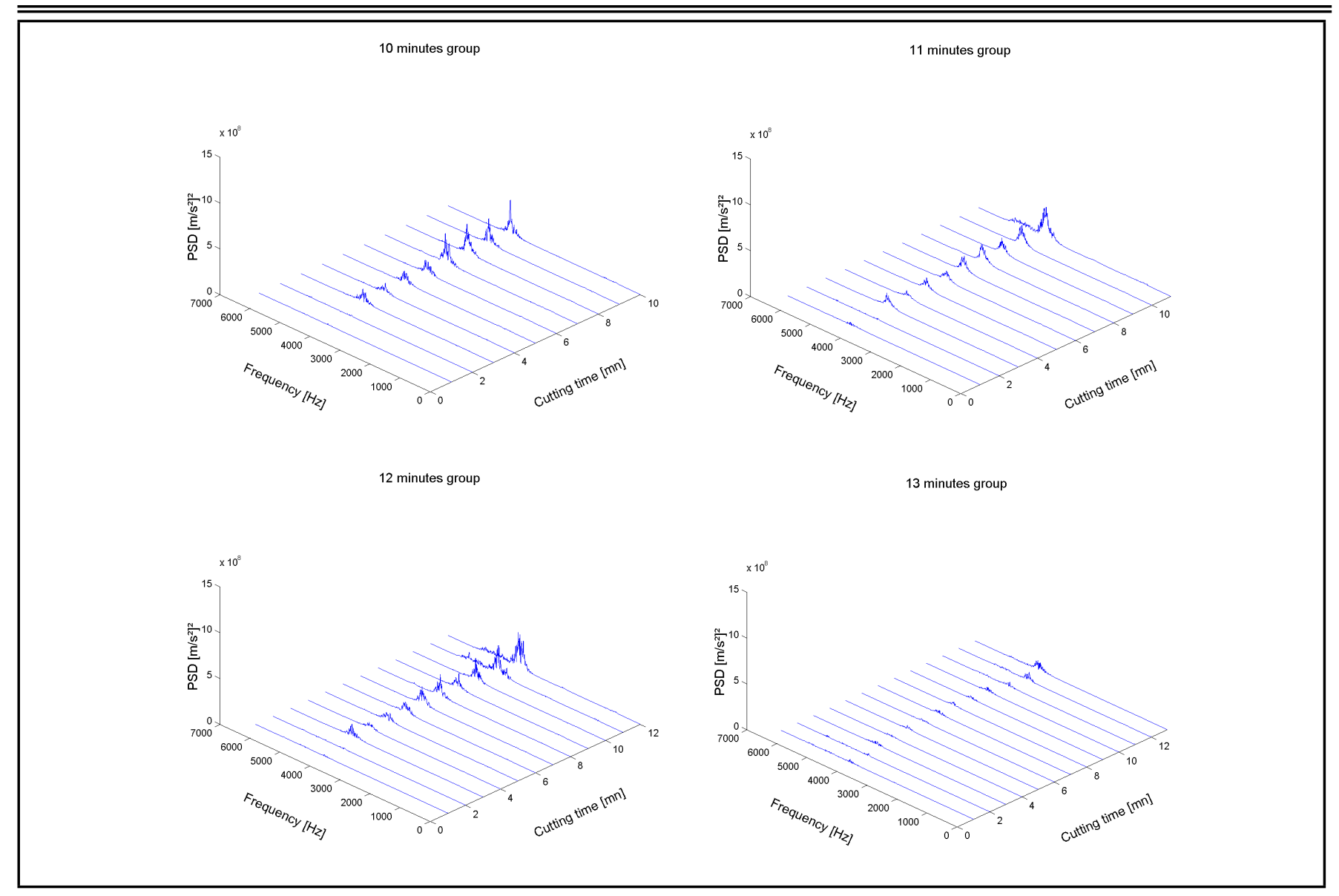

Figure 13. PSD vibration spectra vs experiments for each insert group, respectively, according to Z-direction.

\subsubsection{PSD and Tool Wear}

In order to characterize the evolution of vibratory energy according to the cutting tool wear, the PSD vibration spectra (waterfall plot) is respectively represented in Figs. 11, 12 and 13 , respectively in $\mathrm{X}-$, Y-, and Z-directions.

In these figures, it was possible to visualize the amplitude variations and their corresponding frequencies, and the two frequency bands (one to $4200 \mathrm{~Hz}$ and the other to $5100 \mathrm{~Hz}$ ) were distinguished quite clearly. A third frequency $(2600 \mathrm{~Hz})$ is slightly visible in $\mathrm{X}$-direction of the 11 minutes group (Fig. 11). A previous modal analysis of the cutting tool (tap test) has shown that these three frequencies correspond to the first three natural frequencies of the cutting tool. These frequencies increased steadily, peaking before falling just before the tool collapse.

As illustrated in Fig. 12, the Y-direction imposes the highest levels when compared to the others directions, which is in agreement with the research used in this paper, because it corresponds to the direction of cut where the cutting energy is highest. The magnitude of vibration is higher in the main cutting Y-direction than that of the radial X-direction.

The evolution of these PSD according to the X-direction of acquisition was significant to the deterioration of the tool state. The three conventional phases of tool life (initial wear zone, stabilization, and acceleration of wear) can be distinguished.

Finally, it is clear that the amplitude of vibration increases steadily with increasing flank wear, as it was established for the variance or envelope analysis.
Table 2. Sensitivity matrix of vibration components.

\begin{tabular}{|l|c|c|c|}
\hline & \multicolumn{3}{|c|}{ Vibration components } \\
\hline Criteria & X-Direction & Y-Direction & Z-Direction \\
\hline Variance & 3 & 1 & 2 \\
\hline Envelope & 3 & 1 & 1 \\
\hline Power Spectral Density & 3 & 1 & 2 \\
\hline Total & 9 & 3 & 5 \\
\hline
\end{tabular}

\subsubsection{Comparative Evaluation of Signal Processing Methods}

For the best performance evaluation of the three adapted signal processing methods used, a sensitivity criterion to tool wear was obtained by building a sensitivity index table. Table 2 was constructed using the following score: $3=$ most sensitive; $2=$ moderately sensitive; $1=$ least sensitive; and $0=$ not sensitive at all.

All the components of the vibratory signal were sensitive to flank wear, but the X-Direction component was the most sensitive, regardless of the cutting conditions, to all the adapted signal processing used, i.e. the variance, envelope, and power spectral density.

\section{CONCLUSIONS}

The present study investigates the use of vibration measurement to perform the evaluation of cutting tool wear during the dry turning process. To achieve this objective, tool life tests according to ISO standard 3685 were conducted. The flank wear width of the cutting tool insert was measured using a binocular optical microscope and a 3-D optical profiler after each machining. Thirty inserts used under the same experimental pro- 
tocol were classified into four groups associated with different lifespans, which demonstrated the complexity of the wear phenomenon in an industrial context.

Generally, all cutting tool inserts had the same behaviour according to the tool life law. The level progressively increases with the time of machining. The cutting tool wear may be split, then, into three regions as expected.

From accelerometer data acquired during the dry turning process, three signal processing analyses based on the calculation of the variance, the envelope, and the smoothed mean periodogram of the signals were evaluated. This demonstrated that the variance, the envelope, and the smoothed mean periodogram were relevant parameters for the evaluation of the cutting tool wear from accelerometer data in the X-direction. For any parameter selected, each group respects a certain order. Indeed, the groups which last longest are those whose vibratory level is lowest. In addition, the highest levels were obtained in the cut direction in agreement with the studies used in this paper. Finally, a sensitivity criterion was proposed to choose the most sensitive direction for signal processing analysis from accelerometer signals.

\section{REFERENCES}

1 Dan, L. and Mathew, J. Tool wear and failure monitoring techniques for turning: A review, Int. J. Mach. Tool. Manu., 30 (4), 579598, (1990). http://dx.doi.org/10.1016/08906955(90)90009-8

2 Dimla, E. Sensor signals for tool-wear monitoring in metal cutting operations a review of methods, Int. J. Mach. Tool. Manu., 40, 10731098, (2000). http://dx.doi.org/10.1016/s0890-6955(99)00122-4

3 Lim, G. H. Tool wear monitoring in machine turning, J. Mater. Process. Tech., 51 (14), 2536, (1995). http://dx.doi.org/10.1016/0924-0136(94)01354-4

4 Braun, S. and Lenz, E. Machine tool wear monitoring: mechanical signature analysis: theory and applications, Academic Press Ltd., 321342, (1986).

5 Altintas, Y. Manufacturing Automation, Cambridge University Press, 2000.

6 Cheng, K. Machine dynamics: fundamentals, applications and practices, Springer series in advanced manufacturing, Springer-Verlag London Limited, UK, (2009). http://dx.doi.org/10.1007/978-1-84628-368-0

7 ISO 3685:1993: Tool-life testing with single-point turning tools, (1993), 2nd edition.

8 Kurada, S. and Bradley, C. A review of machine vision sensors for tool condition monitoring, Comput. Ind., 34 (1), 5572, (1997). http://dx.doi.org/10.1016/s01663615(96)00075-9

9 Wang, W. H., Hong, G. S., Wong, Y. S., and Zhu, K. P. Sensor fusion for online tool condition monitoring in milling, Int. J. Prod. Res., 45 (21), 50955116, (2007). http://dx.doi.org/10.1080/00207540500536913
10 Srinivas, J. and Kotaiah, K. Rama. Tool wear monitoring with indirect methods, Manu. Tech. Today (India), 4, 79, (2005).

11 Byrne, G., Dornfeld, D., Inasaki, I., Ketteler, G., Knig, W., and Teti, R. Tool condition monitoring (TCM) The status of research and industrial applications, CIRP Annals, 44 (2), 541568, (1995). http://dx.doi.org/10.1016/s00078506(07)60503-4

12 Micheletti, G. F., et al., In process tool wear sensors for cutting operations, CIRP Annals, 25, 483495, (1976).

13 Rice, J. A. and Wu, S. M. On the feasibility of catastrophic cutting tool fracture prediction via acoustic emission analysis, Transactions of the ASME J. Eng. Ind., 115, 400403, (1993). http://dx.doi.org/10.1115/1.2901781

14 Ravindra, H. V., Srinivasa, Y. G., and Krishnamurthy, R. Modelling of tool wear based on cutting forces in turning, Wear, 169, 2532, (1993). http://dx.doi.org/10.1016/00431648(93)90387-2

15 Oraby, S. E. and Hayhurst, D. R. Tool life determination based on the measurement of wear and tool force ratio variation, Int. J. Mach. Tool. Manu., 44, 12611269, (2004). http://dx.doi.org/10.1016/j.ijmachtools.2004.04.018

16 Choudhury, S. K. and Ramesh, S. On-line tool wear sensing and compensation in turning, J. Mater. Process. Tech., 49, 247254 (1995). http://dx.doi.org/10.1016/09240136(94)01350-a

17 Cuppini, D. and Errico, G. Tool wear monitoring based on cutting power measurement, Wear, 139 (2), 303311, (1990). http://dx.doi.org/10.1016/0043-1648(90)90052-c

18 Scheffer, C. and Heyns, P. S. Wear monitoring in turning operations using vibration and strain measurements, Mech. Syst. Signal Pr., 15, 11851202, (2001). http://dx.doi.org/10.1006/mssp.2000.1364

19 Rmili, W., Ouahabi, A., Serra, R., and Kious, M. Tool wear monitoring in turning process using vibratory analysis, Int. J. Acoust. Vib., 14 (1), 411, (2009).

20 Coromant, S. Turning tools general turning, 2007.

21 Tobias, S. A. Machine tool vibration, Blackie and Son Ltd, London, UK, (1965).

22 Thomas, M., Beauchamp, Y., Youssef, Y. A., and Masounave, J. Effect of tool vibration on surface roughness during lathe dry turning process, Comput. Ind. Eng., 31 (3), 637644, (1995). http://dx.doi.org/10.1016/s03608352(96)00235-5

23 Oppenheim, A. V. and Schafer, R. W. Discrete-time signal processing, 3rd Edition, Pearson, Boston, (2010).

24 Welch, P. D. The use of fast Fourier transform for the estimation of power spectra: a method based on time averaging over short, modified periodograms, IEEE T. Acoust. Speech, 15 (2), 7073, (1967). http://dx.doi.org/10.1109/tau.1967.1161901 